\title{
Psychosexual Care
}

Current systematic reviews on psychosexual concerns cover a range of topics. The most important findings are as follows.

Some tend to focus on aetiology of psychosexual concerns post treatment [1]. Whereas others tend to review psychosocial interventions that can be used to improve communication within this cohort [2]. Other reviews look at quality of life across several cancer types. Specifically for prostate cancer, it was found that patients did have psychosexual concerns post treatment that were unaddressed [3]. Others (Steinke et al. [4]) review literature on rehabilitation, concluding there are no consensus guidelines regarding this. Goldfarb et al. [5], examined sexual health in cancer survivors, and found early intervention (was required post therapy, with fertility preservation in the young. Latini [6] went one step further. They identified psychosexual interventions in studies as a primary goal had better results. Furthermore, they identified that this needed to be personalised and tailored.

\section{References}

1. Bandura A. Swimming against the mainstream: the early years from chilly tributary to transformative mainstream. Behav Res Ther. 2004;42:613-30.

2. Reason P. The Sage handbook of action research: participative inquiry and practice. In: Bradbury H, editor. California: Sage; 2008.

3. Muller-Mattheis V, Schulz C, Schmelzer R, Mortsiefer A, Rotthoff T, Albers P, Karger A. Evaluation of a new course on teaching of erectile dysfunction following pelvic surgery in men with prostate or bladder cancer in undergraduate medical education. J Cancer Res Clin Oncol. 2012;138:124.

4. Steinke EE, Wright DW, Chung ML, Moser DK. Sexual self-concept, anxiety, and self-efficacy predict sexual activity in heart failure and healthy elders. Heart Lung. 2008;37:323-33.

5. Goldfarb S, Mulhall J, Nelson C, Kelvin J, Dickler M, Carter J. Sexual and reproductive health in cancer survivors. Semin Oncol. 2013;40(6):726-44.

6. Latini D. Editorial comment on "The impact of prostate cancer treatment on the sexual quality of life for men-who-have-sex-with-men". J Sex Med. 2015;12(12):2387. 